\title{
An Improved Phase-Locked-Loop Control with Alternative Damping Factors for VSC Connected to Weak AC System
}

\author{
Bin Yuan, Jianzhong Xu, Chengyong Zhao, and Yijia Yuan \\ State Key Laboratory of Alternate Electrical Power System with Renewable Energy Sources, North China Electric Power University, \\ Beijing 102206, China
}

Correspondence should be addressed to Bin Yuan; yuanbingemini@126.com

Received 12 October 2015; Revised 1 January 2016; Accepted 4 January 2016

Academic Editor: Ahmed M. Massoud

Copyright (C) 2016 Bin Yuan et al. This is an open access article distributed under the Creative Commons Attribution License, which permits unrestricted use, distribution, and reproduction in any medium, provided the original work is properly cited.

\begin{abstract}
The gains of phase-locked-loop (PLL) have significant impacts on the power transfer limits for the voltage source converter (VSC) connected to weak AC system. Therefore, in this paper, an improved PLL control, respectively, with alternative damping factors for rectifier and inverter is proposed. First, it is proved that the impedance angle of AC system has a great impact on the small-signal stability of the VSC system. With the same variation tendency of Thévenin equivalent resistance, the limits of power transmission are changing in opposite trends for rectifier and inverter. Second, the improved PLL with alternative damping factors is proposed based on the participation factor analysis. Third, the optimal damping factors of the improved PLL control for rectifier and inverter are calculated. Simulations and calculations validated the following three conclusions: (1) in rectifying operation, the equivalent system resistance has a negative impact on the stability of the system and this is not the case for inverting operation; (2) adding the alternative damping factors to PLL control shows similar results compared with changing the impedance angle of AC system; (3) the proposed optimal damping factors of PLL can effectively extend the power transfer limits under both rectifier and inverter modes.
\end{abstract}

\section{Introduction}

Renewable energy resources are emerging as a future energy vector, and the voltage source converters (VSCs) are widely used to integrate such energies into power system [1-4]. The VSC-HVDC link connected to weak AC system with very low short circuit ratio (SCR $<2$ ) will emerge quite often in the future [5-7]. However, the conventional vector-current control in $d-q$ frame exhibits poor dynamic performance when applied to VSC connected to it. This brings a problem that the transmitted power cannot reach the ideal limitation for the unstable of small-signal model [8-17].

There are three possible approaches to solve this problem. The first approach is shown in [8], which proposed an advanced vector-current control to decouple the $d$-q outerloop control completely by optimizing the control parameters. However, the provided method is quite complicated and it is not suitable for frequent and rapid power changing.

The second approach shown in [9] is adopting power synchronization control (PSC) as the main control strategy.
PSC is similar with power angle control. This control strategy will not cause stable operating problems in extremely weak AC systems. However, it behaves in relatively low response speed due to the lack of the inner-loop current control and hence it cannot satisfactorily meet the requirement of the AC system.

The last approach shown in [10] is changing the parameters of phase-locked-loop (PLL), especially the proportional gain in PI controller. It has been recognized that the challenging for VSCs operating in weak AC system is caused by the PLL dynamics. The response speed and small-signal stability are contradictory characteristics of the system. With a high proportional gain, the system response becomes quicker while the power transfer limitations decrease. Further, [16] reported that PLL has negative impact on the stability of VSC connected to weak AC system with reduced order model. However, quite few literatures have attempted to optimize PLL control system to enhance the stability of VSCs connected to weak AC system. 


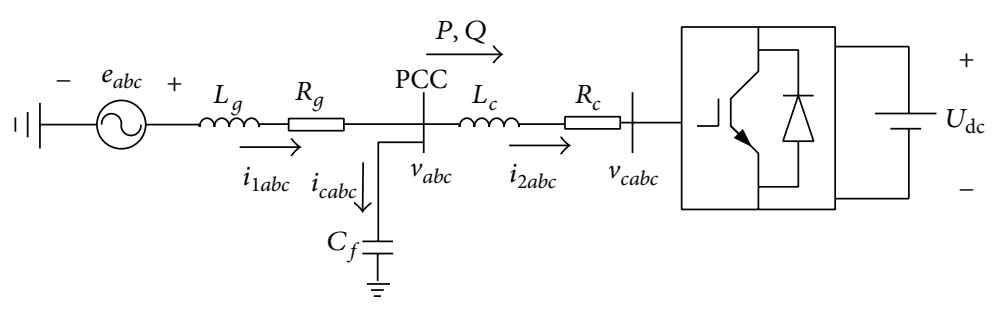

FIGURE 1: The benchmark test model of VSC connected to weak AC system.

This paper aims to propose an improved PLL control to extend the power transfer limitations. In the research of this work, it has been recognized that the impedance angle of weak AC system can also influence the power transfer limits. Meanwhile, an important observation is that for VSCs under different operation modes the equivalent resistance (related to the impedance angle directly) has opposite effects on the stability of VSCs. An advanced PLL with damping factor is proposed in this paper to enhance the power transfer limitations of grid-connected VSCs.

The rest of this paper is organized as follows. Section 2 presents the fundamental analysis of VSC connected to weak AC system. Section 3 studies the influence on power transfer limitations caused by impedance angle. Section 4 proposes an advanced PLL control system to enhance the stability of VSC connected to weak AC system. Section 5 verifies the proposed control by several case studies. And Section 6 concludes this paper.

\section{Small-Signal Model of VSC Connected to Weak AC System}

2.1. Benchmark Test Model. A two-level VSC is adopted in this paper as the topology. The test model is shown in Figure 1. The weak AC system is represented by a Thévenin equivalent circuit and the equivalent impedance is $R_{g}+j \omega L_{g}$. The DC side of the converter is represented by a DC voltage source. With the consideration of the current limitation of transformer, a capacitor is shunted at PCC to provide reactive power compensation. $L_{c}$ is the leakage inductance of transformer and $R_{c}$ is the resistance between PCC and converter.

Vector-current control is selected as system control strategy and the control diagram is shown in Figure 2(a). Active power $(P)$ control and AC voltage $(V)$ control are adopted. Direct and quadrature current reference signals for the inner-loop are generated from outer-loop control [18]. The simplified PLL model [19] is shown in Figure 2(b). With PI controller, the quadrature voltage at PCC point equals zero and the voltage phase angle can be accurately locked and measured.

2.2. System and Control Equations. The state-space model derived in this paper includes AC system and VSC controller shown in Figures 1 and 2, respectively.
2.2.1. AC System Equations. The equations of AC system are

$$
\begin{aligned}
{\left[\begin{array}{l}
e_{d} \\
e_{q}
\end{array}\right]-\left[\begin{array}{c}
v_{d} \\
v_{q}
\end{array}\right]=} & R_{g}\left[\begin{array}{l}
i_{1 d} \\
i_{1 q}
\end{array}\right]+L_{g} \frac{d}{d t}\left[\begin{array}{c}
i_{1 d} \\
i_{1 q}
\end{array}\right] \\
& +\omega L_{g}\left[\begin{array}{c}
-i_{1 q} \\
i_{1 d}
\end{array}\right], \\
{\left[\begin{array}{c}
v_{d} \\
v_{q}
\end{array}\right]-\left[\begin{array}{l}
v_{c d} \\
v_{c q}
\end{array}\right]=} & R_{c}\left[\begin{array}{c}
i_{2 d} \\
i_{2 q}
\end{array}\right]+L_{c} \frac{d}{d t}\left[\begin{array}{c}
i_{2 d} \\
i_{2 q}
\end{array}\right] \\
& +\omega L_{c}\left[\begin{array}{l}
-i_{2 q} \\
i_{2 d}
\end{array}\right], \\
{\left[\begin{array}{c}
i_{1 d} \\
i_{1 q}
\end{array}\right]-\left[\begin{array}{l}
i_{2 d} \\
i_{2 q}
\end{array}\right]=} & C_{f} \frac{d}{d t}\left[\begin{array}{c}
v_{d} \\
v_{q}
\end{array}\right]+\omega C_{f}\left[\begin{array}{c}
-v_{q} \\
v_{d}
\end{array}\right] .
\end{aligned}
$$

In this case, $e_{d}$ equals $E_{m} \cos \delta$ and $e_{q}$ equals $-E_{m} \sin \delta$ and $\delta$ is the angle to which PCC voltage $\mathbf{V}$ leads equivalent AC system voltage $\mathbf{E}$.

2.2.2. Control System Equations. Active power control and AC voltage control are adopted as system control. $P_{\text {ref }}$ and $V_{\text {ref }}$ are the references for active power and AC RMS voltage. Inner-loop references of direct current $i_{2 d \text { ref }}$ and quadrature current $i_{2 q \text { ref }}$ are calculated by outer-loop control:

$$
\begin{aligned}
& k_{\mathrm{pp}}\left(P_{\text {ref }}-P\right)+k_{\mathrm{ip}} \int\left(P_{\text {ref }}-P\right) d t=i_{2 d \mathrm{ref}}, \\
& k_{\mathrm{pv}}\left(V_{\text {ref }}-V\right)+k_{\mathrm{iv}} \int\left(V_{\text {ref }}-V\right) d t=i_{2 q \mathrm{ref}} .
\end{aligned}
$$

The inner-loop control equations are shown in

$$
\begin{aligned}
& k_{p 1}\left(i_{2 d \mathrm{ref}}-i_{2 d}\right)+k_{i 1} \int\left(i_{2 d \mathrm{ref}}-i_{2 d}\right) d t \\
& =L_{c} \frac{d i_{2 d}}{d t}+R_{c} i_{2 d}
\end{aligned}
$$




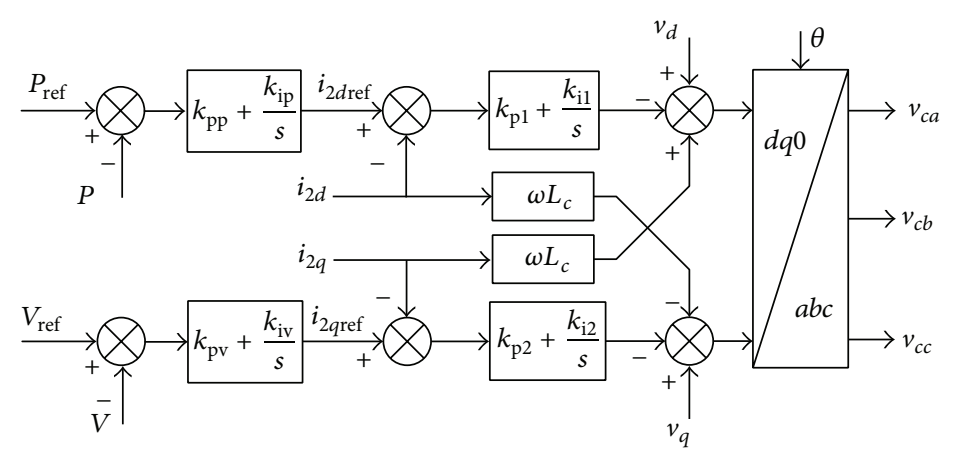

(a) Vector-current control model

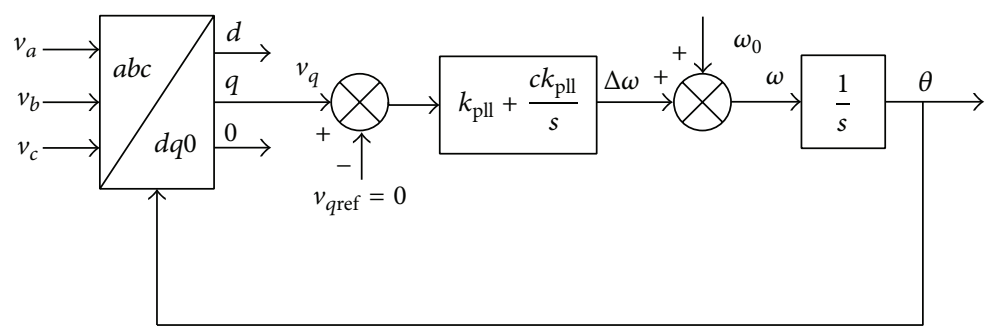

(b) The simplified model of PLL

FIGURE 2: Control diagram of VSC connected to weak AC system.

$$
\begin{aligned}
& k_{p 2}\left(i_{2 q \mathrm{ref}}-i_{2 q}\right)+k_{i 2} \int\left(i_{2 q \mathrm{ref}}-i_{2 q}\right) d t \\
& =L_{c} \frac{d i_{2 q}}{d t}+R_{c} i_{2 q} .
\end{aligned}
$$

The simplified PLL model is given by

$$
\begin{aligned}
& \omega=\omega_{0}+k_{\mathrm{pll}} v_{q}+c k_{\mathrm{pll}} \int v_{q} d t, \\
& \theta=\int \omega d t .
\end{aligned}
$$

In this paper, $\omega_{0}$ is specified as $100 \pi \mathrm{rad} / \mathrm{s}$.

2.2.3. State-Space Model. The detailed derivation of the statevariable equations is given in the Appendix. Considering that the references of active power and AC voltage are not supposed to change for small-signal model, both $\Delta P_{\text {ref }}$ and $\Delta V_{\text {ref }}$ equal zero. The linearized state-space model is given by

$$
\Delta \dot{\mathbf{X}}=\mathbf{A} \Delta \mathbf{X}
$$

in which $\Delta \mathbf{X}=\left[\Delta i_{1 d}, \Delta i_{1 q}, \Delta i_{2 d}, \Delta i_{2 q}, \Delta v_{d}, \Delta v_{q}, \Delta x_{1}, \Delta x_{2}\right.$, $\left.\Delta x_{3}, \Delta x_{4}, \Delta \theta, \Delta x_{5}\right]^{T}$. A is a 12 -order matrix (the former 6 variables are $\mathrm{AC}$ system variables and the others are control system variables). The detailed information of matrix $\mathbf{A}$ and the definitions of $x_{1} \sim x_{5}$ are shown in the Appendix.

The operating point of VSC system and the power

\begin{tabular}{|c|c|c|}
\hline & Parameter symbols & Value \\
\hline \multirow{7}{*}{$\begin{array}{l}\text { Main circuit } \\
\text { parameters }\end{array}$} & $\begin{array}{c}\text { Equivalent } \mathrm{AC} \text { source } \\
\text { voltage } E\end{array}$ & $1.0 \mathrm{pu}, 50 \mathrm{~Hz}$ \\
\hline & $\begin{array}{c}\text { Equivalent impedance } \\
\text { of AC system } \\
R_{g}+j X_{g}\end{array}$ & $\begin{array}{l}0.547+j 0.048 \mathrm{pu} \text {, } \\
\text { impedance angle } 85^{\circ}\end{array}$ \\
\hline & $\begin{array}{c}\text { Equivalent AC system } \\
\text { SCR }\end{array}$ & 1.83 \\
\hline & $\begin{array}{c}\text { Rated DC power } \\
\text { rating }\end{array}$ & $1.0 \mathrm{pu}$ \\
\hline & PCC voltage & $1.0 \mathrm{pu}$ \\
\hline & $\begin{array}{l}\text { Converter impedance } \\
\qquad R_{c}+j X_{c}\end{array}$ & $0.003+j 0.15 \mathrm{pu}$ \\
\hline & Capacitor $C_{f}$ & $0.15 \mathrm{pu}$ \\
\hline \multirow{5}{*}{$\begin{array}{l}\text { Controller } \\
\text { parameters }\end{array}$} & $\begin{array}{l}\text { Power controller } \\
\text { gains }\left(k_{\mathrm{pp}}, k_{\mathrm{ip}}\right)\end{array}$ & $(0.5,50)$ \\
\hline & $\begin{array}{l}\text { AC voltage controller } \\
\text { gains }\left(k_{\mathrm{pv}}, k_{\mathrm{iv}}\right)\end{array}$ & $(0.35,30)$ \\
\hline & $\begin{array}{l}\text { Inner } i_{d} \text { controller } \\
\text { gains }\left(k_{p 1}, k_{i 1}\right)\end{array}$ & $(1,10)$ \\
\hline & $\begin{array}{l}\text { Inner } i_{q} \text { controller } \\
\text { gains }\left(k_{p 2}, k_{i 2}\right)\end{array}$ & $(1,10)$ \\
\hline & PLL gains $\left(k_{\mathrm{pll}}, c\right)$ & $(50,10)$ \\
\hline
\end{tabular}
controller parameters are shown in Table 1.

The eigenvalues of test model at the operating point of $P_{\text {ref }}=1.33$ and $P_{\text {ref }}=1.50$ are shown in Table 2 .
TABLE 1: Parameters of VSC connected to weak AC system.

With the eigenvalues shown in Table 2 (see the bold italic), the predominant poles [20] of matrix $\mathbf{A}$ are selected to be $\lambda_{8,9}$. The root-locus of $\lambda_{8,9}$ with active power changing is shown in Figure 3. And some of the values in Figure 3 are picked up and shown in Table 3. 
TABLE 2: Eigenvalues of the test model.

\begin{tabular}{lcc}
\hline & $\mathrm{SCR}=1.37\left(P_{\mathrm{ref}}=1.33 \mathrm{pu}\right)$ & $\mathrm{SCR}=1.22\left(P_{\text {ref }}=1.5 \mathrm{pu}\right)$ \\
\hline$\lambda_{1}$ & -1510 & -1509 \\
$\lambda_{2,3}$ & $-304 \pm j 1120$ & $-366.9 \pm j 1180.6$ \\
$\lambda_{4}$ & -1010 & -840.6 \\
$\lambda_{5,6}$ & $-46.3 \pm j 629$ & $-78.4 \pm j 631.3$ \\
$\lambda_{7}$ & -61.29 & -59.8 \\
$\lambda_{8,9}$ & $-\mathbf{5 . 3} \pm \mathbf{j 2 3 . 1}$ & $\mathbf{5 . 2} \pm \mathbf{j 2 1 . 7}$ \\
$\lambda_{10}$ & -11.18 & -10.8 \\
$\lambda_{11}$ & -99.54 & -10 \\
$\lambda_{12}$ & -99.92 & -10 \\
\hline
\end{tabular}

TABLE 3: The detailed information of predominant poles.

\begin{tabular}{lccc}
\hline$P$ & $\lambda_{8,9}$ & Damping ratio & $\begin{array}{c}\text { Oscillation } \\
\text { frequency }(\mathrm{Hz})\end{array}$ \\
\hline $1.30 \mathrm{pu}$ & $-9.86 \pm j 24.08$ & 0.379 & 3.83 \\
$1.33 \mathrm{pu}$ & $-5.30 \pm j 23.10$ & 0.224 & 3.68 \\
$1.37 \mathrm{pu}$ & $-2.80 \pm j 22.00$ & 0.126 & 3.50 \\
$1.40 \mathrm{pu}$ & $0.22 \pm j 21.90$ & - & 3.48 \\
$1.43 \mathrm{pu}$ & $1.51 \pm j 21.71$ & - & 3.46 \\
\hline
\end{tabular}

Figure 3 and Table 3 both show that, with the power rising, the small-signal stability of test model is getting worse and system becomes unstable when the active power reaches about 1.4 pu.

2.2.4. Participation Factor Analysis. Participation factor can be utilized to analyze the relationship between predominant poles and state-variables [21-23]. The participation factor of test model is shown in Table 4.

From Table 4, it can be discovered that the outer-loop and PLL control diagrams are likely to have more impacts on the stability of VSC connected to weak AC system. Reference [8] has proposed the outer-loop control approach, and this paper will mainly focus on the PLL improvements.

\section{The Impacts of System Impedance Angle on Power Transfer Limitations}

This section will analyze the impact of the system impedance angle on VSC working in either rectifier or inverter modes regarding the power transfer limitations.

The active power transmission at PCC can be calculated using

$$
P=\frac{V}{R_{g}^{2}+X_{g}^{2}}\left(-E X_{g} \sin \delta+E R_{g} \cos \delta-V R_{g}\right) .
$$

The power angle curves for different impedance angles $(\varphi)$ of AC system are shown in Figure 4. It can be found that

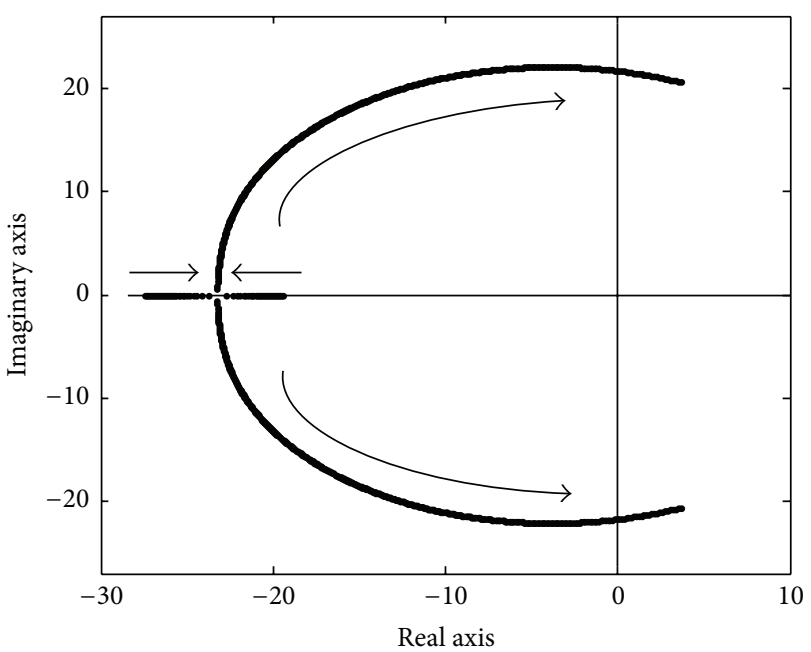

Figure 3: Root-locus of the predominant poles.

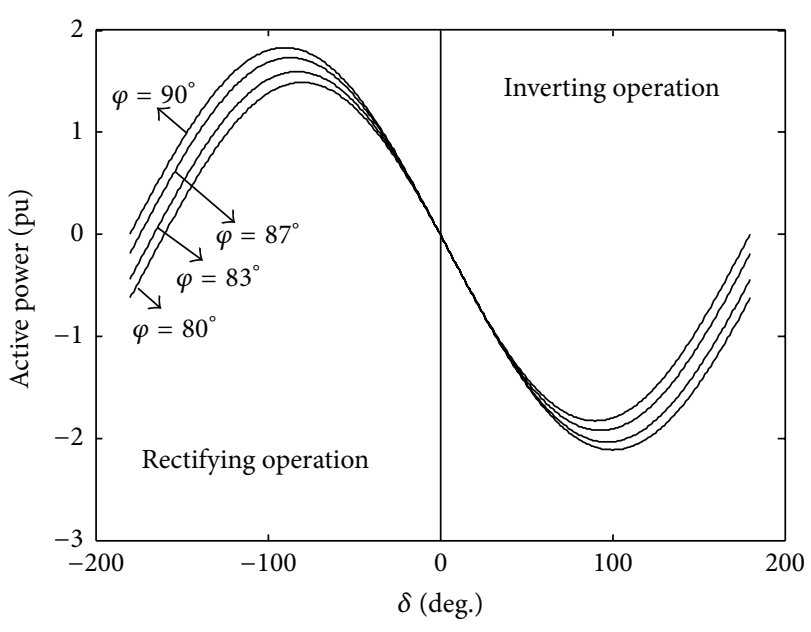

Figure 4: Power angle curves in different impedance angles.

$\varphi$ has a great influence on power transfer limits. The smallsignal stability of VSC system with different $\varphi$ will be analyzed in the subsections below.

3.1. Rectifying Operation. With the analysis of state-space matrix $\mathbf{A}$, it is concluded that the equivalent resistance of AC system has a negative impact on VSC operating as a rectifier. The root-locus of predominant poles with $\varphi$ changing is shown in Figure 5(a). It shows that, for VSC operating in rectifier mode, lower resistance of AC system will enhance the small-signal stability of VSC system.

3.2. Inverting Operation. Again, with the analysis of statespace matrix $\mathbf{A}$, an opposite conclusion can be drawn that, for VSC working in inverter mode, lower resistance of AC system will weaken the VSC system stability, as shown in Figure 5(b).

The power transfer limitations of system with different $\varphi$ are expressed in Table 5. 
TABLE 4: The calculated participation factors of test model.

\begin{tabular}{lccc}
\hline State-variable & Participation factor & State-variable & Participation factor \\
\hline $\mathbf{X}_{1}$ & 0.0277 & $\boldsymbol{X}_{7}$ & $\mathbf{0 . 1 9 0 4}$ \\
$\mathbf{X}_{2}$ & 0.0582 & $\boldsymbol{X}_{8}$ & $\mathbf{0 . 1 7 7 3}$ \\
$\mathbf{X}_{3}$ & 0.0032 & $\mathbf{X}_{9}$ & 0.0014 \\
$\mathbf{X}_{4}$ & 0.0087 & $\mathbf{X}_{10}$ & 0.0037 \\
$\mathbf{X}_{5}$ & 0.0098 & $\boldsymbol{X}_{11}$ & $\mathbf{0 . 3 6 3 9}$ \\
$\mathbf{X}_{6}$ & 0.0040 & $\boldsymbol{X}_{12}$ & $\mathbf{0 . 1 5 1 7}$ \\
\hline
\end{tabular}

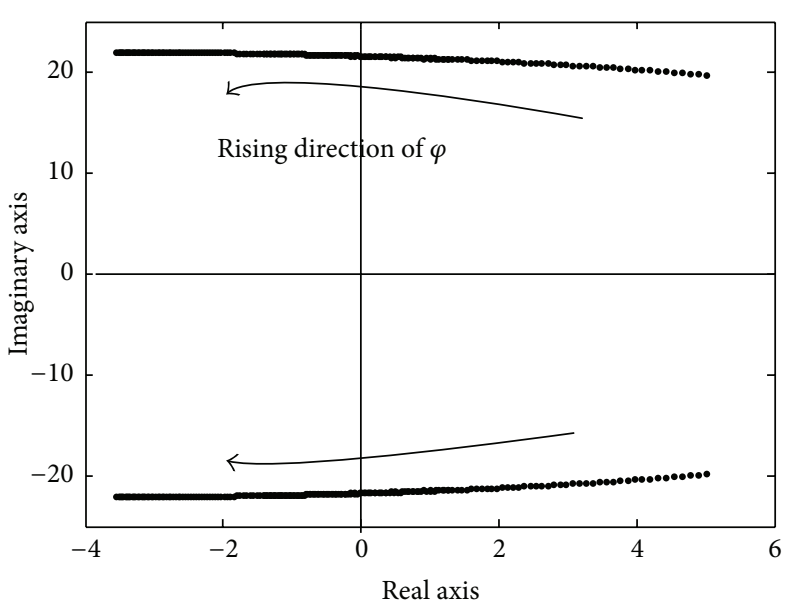

(a) Rectifier

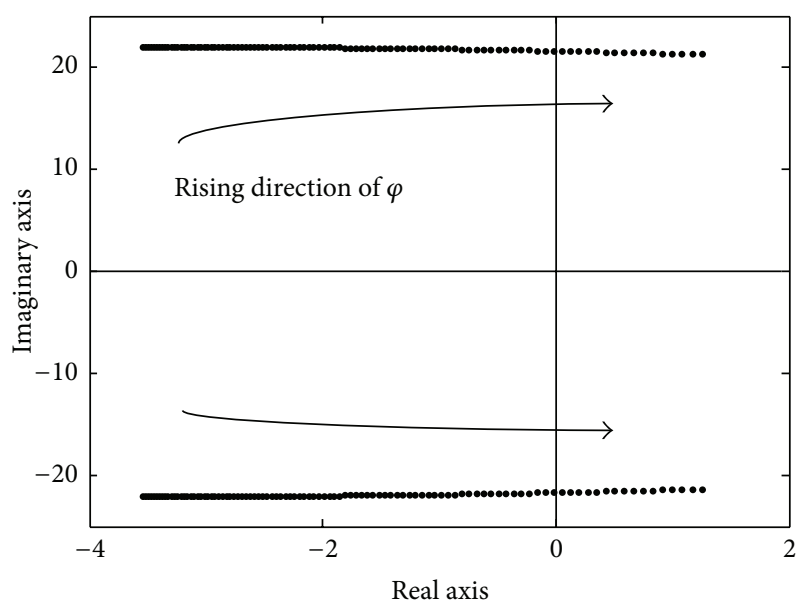

(b) Inverter

FIGURE 5: Root-locus of predominant poles with $\varphi$ change.

TABLE 5: Calculation result of power transfer limitations with different $\varphi$.

\begin{tabular}{lcc}
\hline$\varphi$ & Max $P$ (rectifier) & Max $P$ (inverter) \\
\hline $80^{\circ}$ & 1.284 & 1.533 \\
$81^{\circ}$ & 1.302 & 1.524 \\
$82^{\circ}$ & 1.323 & 1.521 \\
$83^{\circ}$ & 1.358 & 1.518 \\
$84^{\circ}$ & 1.383 & 1.510 \\
$85^{\circ}$ & 1.400 & 1.505 \\
\hline
\end{tabular}

It can be concluded that lower resistance will enlarge the stable margin of VSC working at rectifier mode and will reduce the stable margin for inverter mode.

\section{Improved PLL Control for VSC Connected to Weak AC System}

In Section 3, a conclusion can be drawn that the damping characteristic of AC network (impedance angle) has a great influence on the system stability. With the analysis of participation factor, it is acknowledged that PLL control also has a great impact on the stability of VSC connected to weak AC system. Therefore, an improved PLL control suitable for VSC connected to weak AC system is proposed as follows, which is the main contribution of this paper.
Considering that the active power is proportional to the direct-axis current, a supplementary damping control with state-variable $i_{2 d}$ is added in PLL control system ( $D$ is the damping factor). And the new PLL equations are shown in (7), in which “+” is for rectifying operation and “-” is for inverting operation. Figure 6 shows the improved PLL control diagram:

$$
\begin{aligned}
& \omega=\omega_{0}+k_{\mathrm{pll}} v_{q}+c k_{\mathrm{pll}} \int v_{q} d t, \\
& \theta=\int\left[\omega \pm D\left(i_{2 d \mathrm{ref}}-i_{2 d}\right)\right] d t .
\end{aligned}
$$

The small-signal model is changed and the state-variable matrix A with the improved PLL is shown in the Appendix. Figure 7 shows the root-locus of predominant poles of the modified A.

From Figure 7, it can be seen that, with the rising of damping factor $D$ in a certain range, the small-signal stability of VSC system is enhanced. After a critical value, the stability is reduced with the rising of $D$. The root-locus of VSC system with $P$ rising in different damping factors has also verified the effectiveness of the improved PLL controller. Figure 7(c) shows that, with a proper damping factor, the relationship between PLL and dominant poles is weak. It also means that the most effective parts are changing from PLL to the outer-loop controller, which is the purpose of the improved PLL control strategy. There should be an optimal value for 


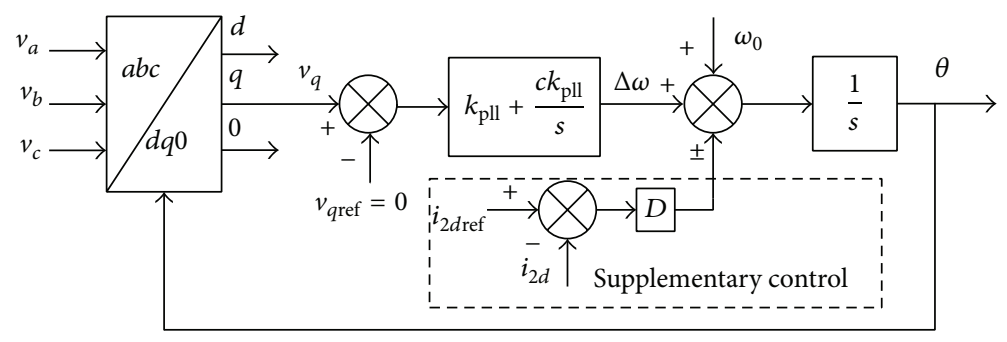

+ is for rectifying operation

- is for inverting operation

FIGURE 6: Improved PLL control for VSC connected to weak AC system.

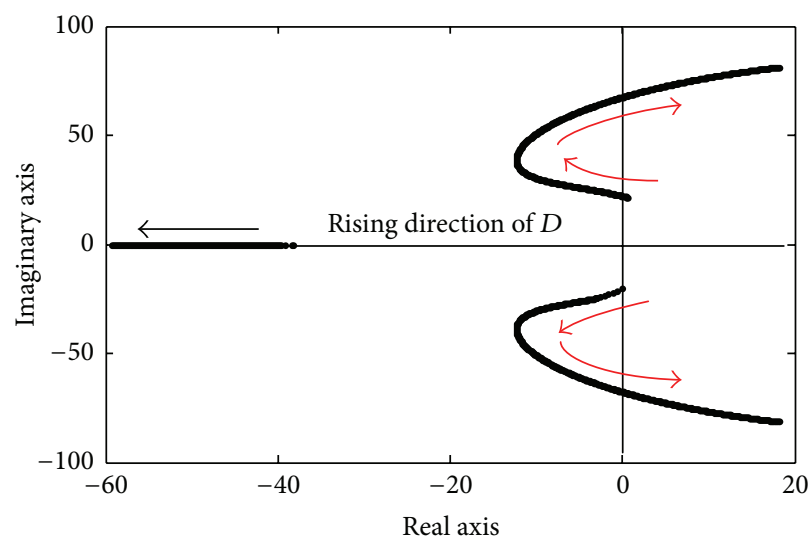

(a) Root-locus of VSC with $P=1.4 \mathrm{pu}$

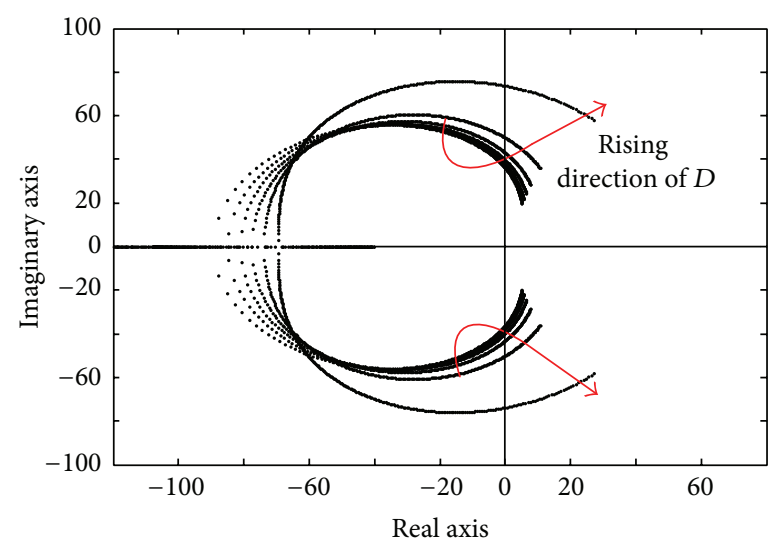

(b) Root-locus of VSC with different transfer power

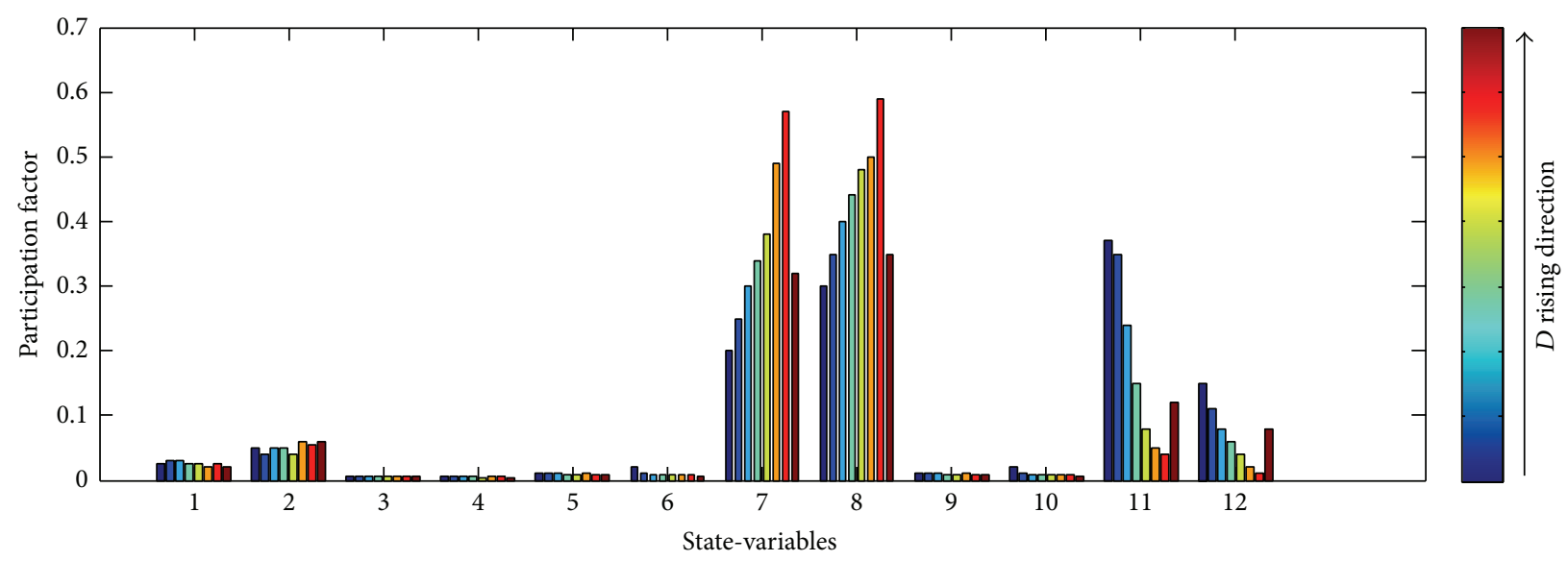

(c) Participation factor analysis

FIGURE 7: Root-locus and participation factor of system with advanced PLL control.

the damping factor $D$. When impedance angle of AC system is $85^{\circ}$, the optimal value of $D$ is approximately 1100 for rectifying operation and 300 for inverting operation.

\section{Case Studies}

5.1. Validation of the Small-Signal Model. Table 6 shows the base values of the system parameters of benchmark test model. The accuracy of the small-signal model including the oscillation frequency and damping ratio will be verified in this section.

Figure 8 shows the simulation results of the system in which the impedance angle is $85^{\circ}$. The active power, PCC voltage, and $D$ - and $Q$-axis current are shown in Figures $8(\mathrm{a}) \sim 8(\mathrm{~d})$ respectively, with the active power being changing from $360 \mathrm{MW}$ to $370 \mathrm{MW}$.

It can be seen from Figure 8 that the maximum error value between EMT model and small-signal model of active power 


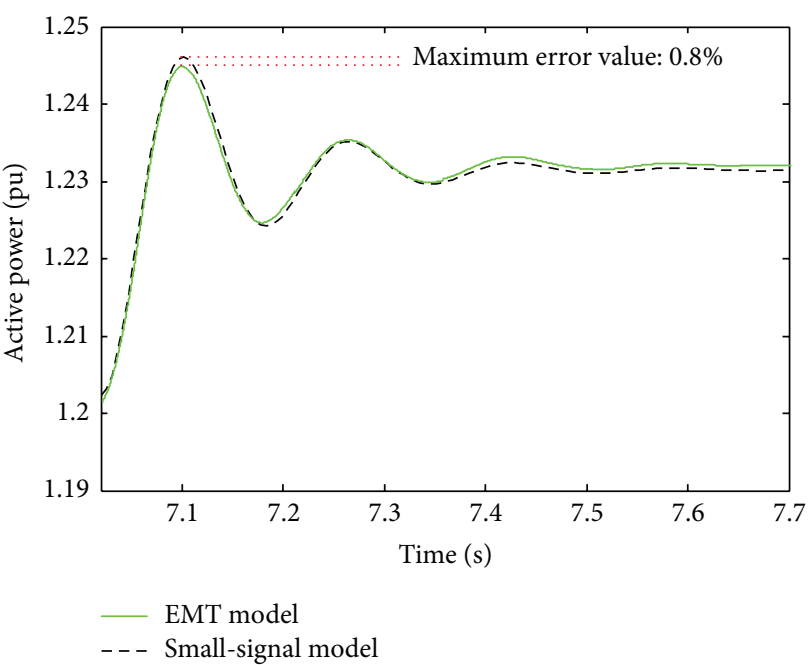

(a) Active power

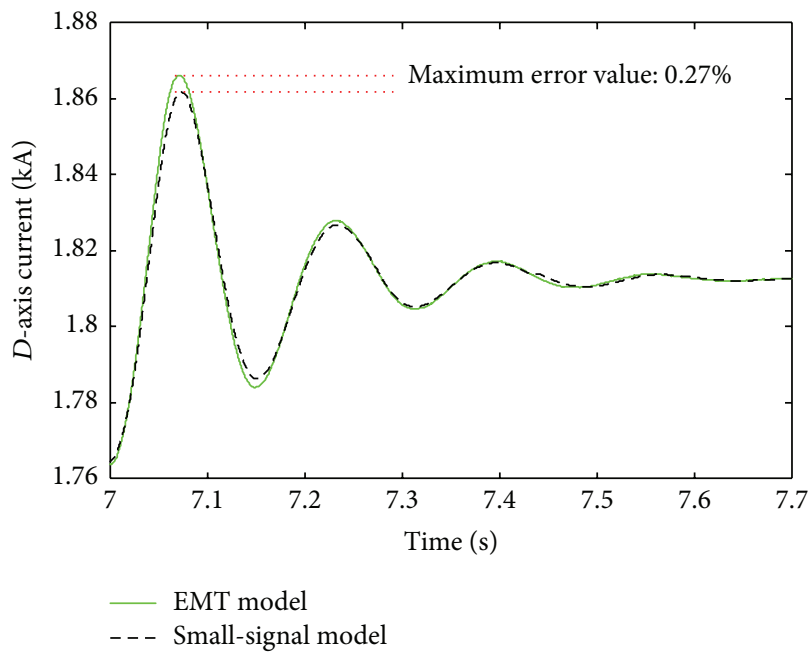

(c) $D$-axis current

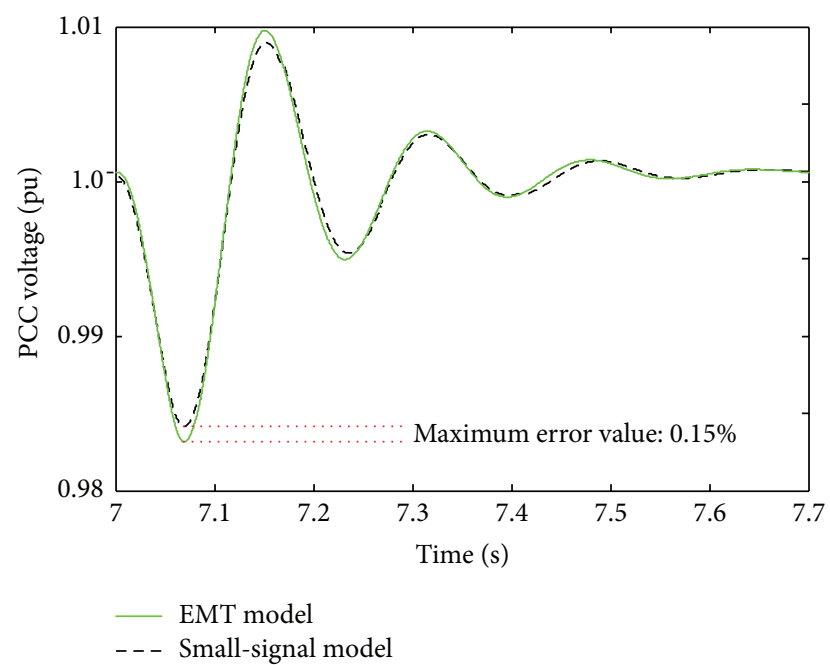

(b) PCC voltage

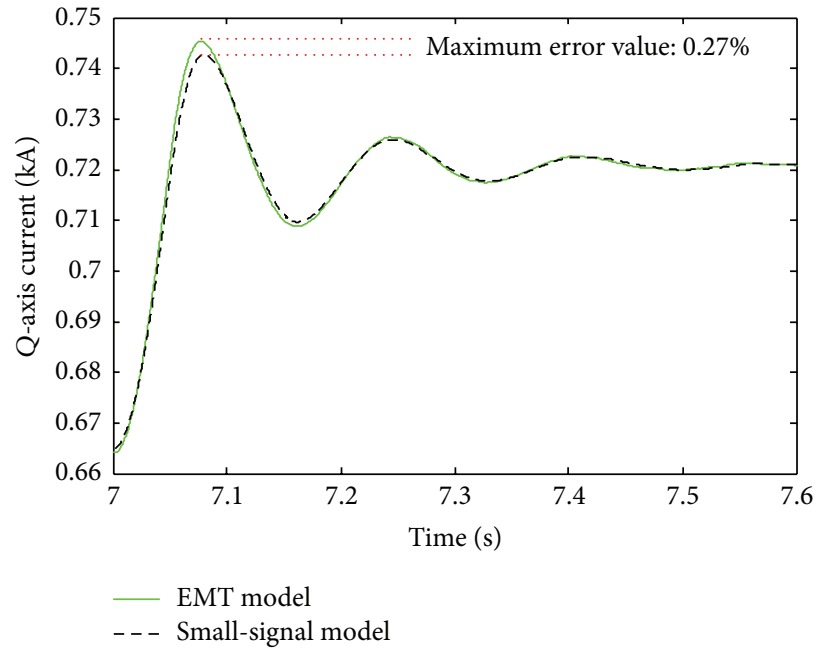

(d) Q-axis current

FIGURE 8: Simulation results of VSC system (impedance angle is $85^{\circ}$ ).

TABLE 6: Parameters of test model.

\begin{tabular}{lc}
\hline Parameters & Value \\
\hline Dc voltage & $\pm 200 \mathrm{kV}$ \\
Rated active power & $300 \mathrm{MW}$ \\
Equivalent AC source voltage & $230 \mathrm{kV}$ \\
PCC voltage & $230 \mathrm{kV}$ \\
Transformer & $230 \mathrm{kV} / 204.12 \mathrm{kV}$
\end{tabular}

is $0.8 \%$. The maximum value of PCC voltage is $0.15 \%$. The maximum error value of $D$-axis current and $Q$-axis current both is $0.27 \%$. Therefore, the correctness of the VSC system small-signal model is satisfactorily validated.

5.2. Validations of Impacts of Impedance Angle on Power Transfer Limits. The theory on the impact caused by impedance angle on stability of VSC connected to weak AC system which is proposed in Section 3 is verified in this section.

5.2.1. Rectifying Operation. Figure 9 shows the maximum power transmission of system with different impedance angles.

It can be seen from the figure that the maximum active power is $385 \mathrm{MW}$ when $\varphi$ equals $80^{\circ}$. Meanwhile, the maximum active power is $420 \mathrm{MW}$ when $\varphi$ equals $85^{\circ}$. Simulation results show that, with the rising of impedance angle, the VSC system operating in rectifier mode gets larger small-signal stable margin.

5.2.2. Inverting Operation. Figure 10 shows the maximum power transmission of system with different impedance angles.

However, the simulation results shown in Figure 10 are opposite with the system working in rectifying operation. 


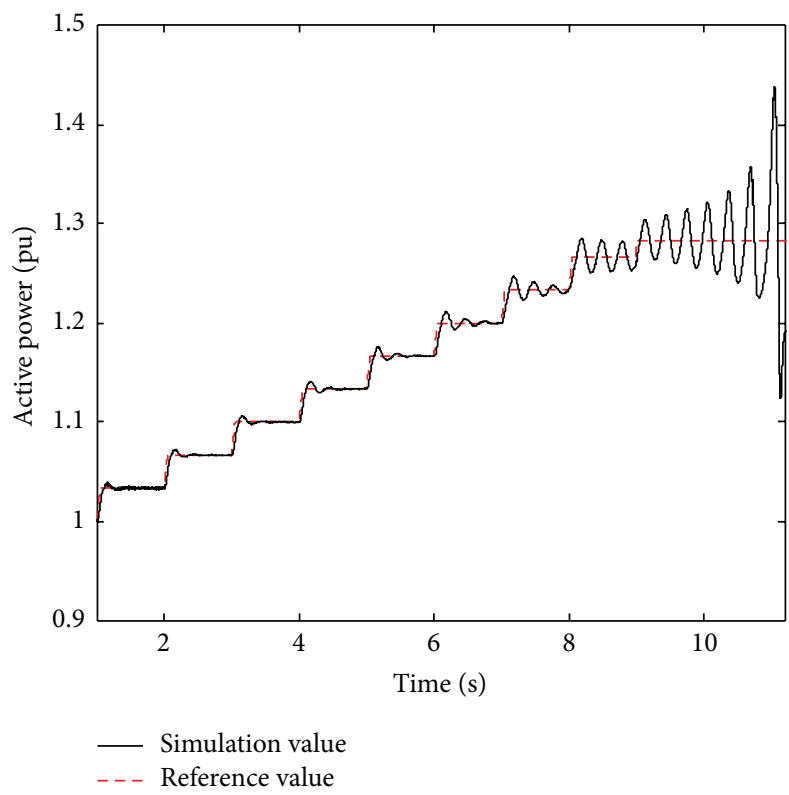

(a) $\varphi=80^{\circ}$

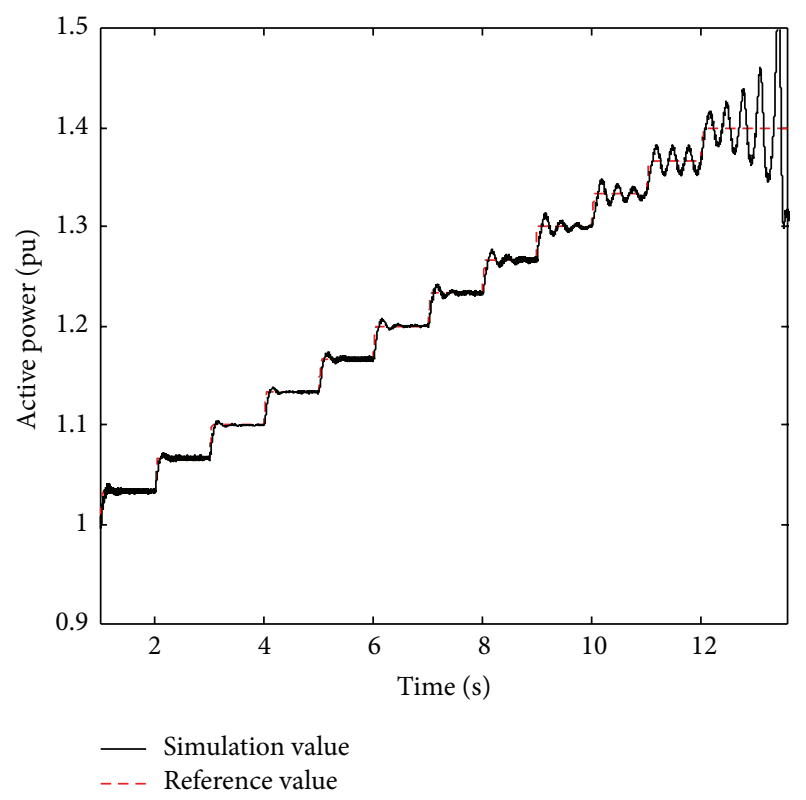

(b) $\varphi=85^{\circ}$

FIGURE 9: Maximum power transmission with different impedance angles (rectifying operation).

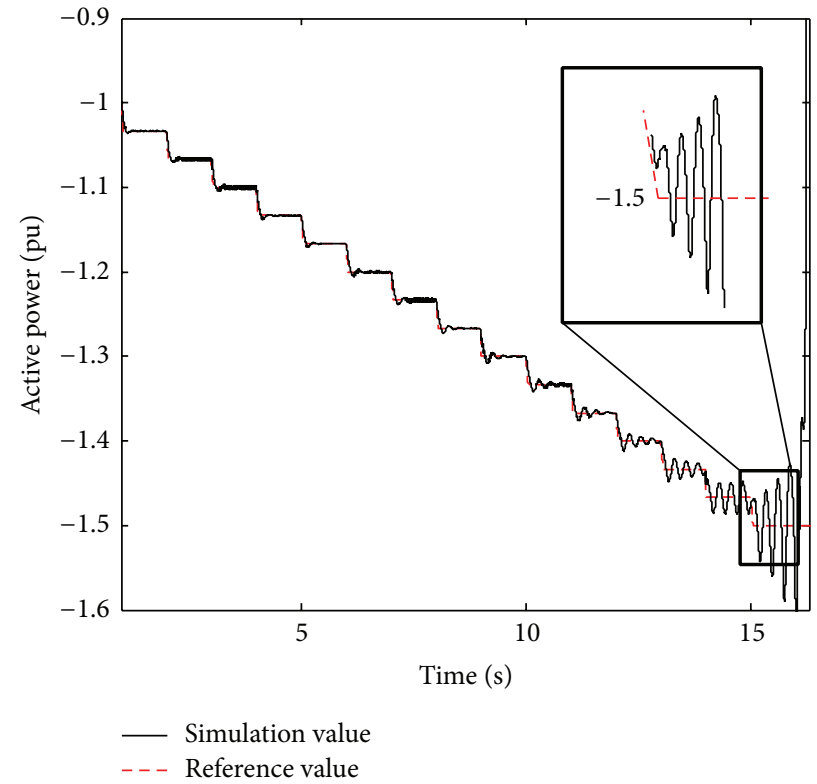

(a) $\varphi=85^{\circ}$

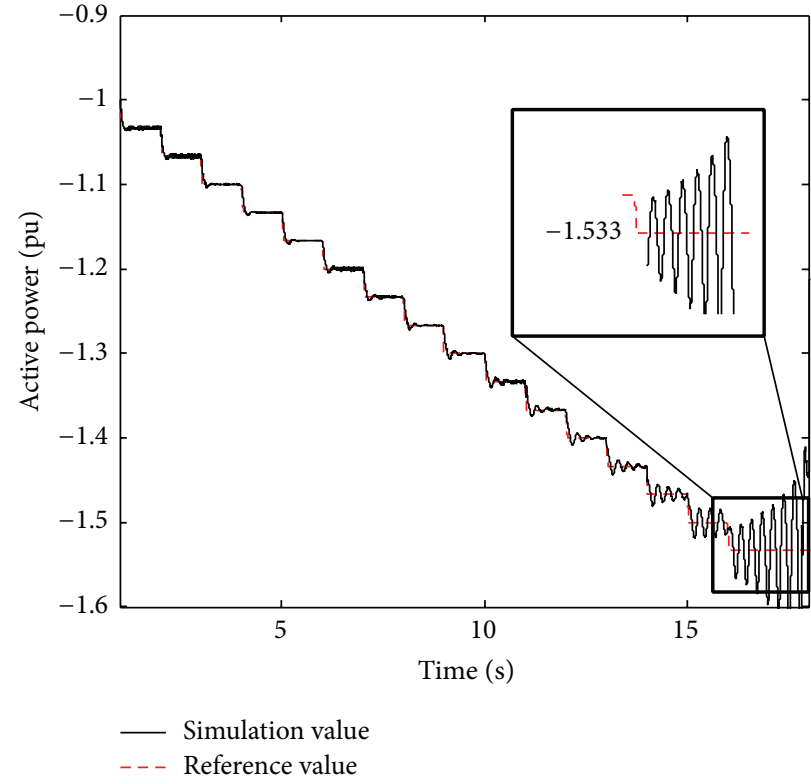

(b) $\varphi=80^{\circ}$

FiguRE 10: Maximum power transmission with different impedance angles (inverting operation).

The maximum active power is $460 \mathrm{MW}$ when $\varphi$ equals $80^{\circ}$, and this value decreased to $450 \mathrm{MW}$ when $\varphi$ equals $85^{\circ}$. With the rising of impedance angle, the VSC system operating in inverter mode is getting smaller stable margin and even becoming unstable.

Table 7 shows the power transfer limitations with different impedance angles.

The conclusion drawn from Section 3 is validated by Table 7. Meanwhile, it can be seen that the system operating at rectifier mode is more severe than inverter mode, which means that the stable margin for VSC working in rectifier mode is narrower than that of inverter mode.

5.3. Validations of the Proposed PLL Control. Figure 11 shows the simulation results of maximum power transmission with the proposed improved PLL control.

It can be obtained that, with the proposed PLL control strategy, the limits of power transmission are improved. 


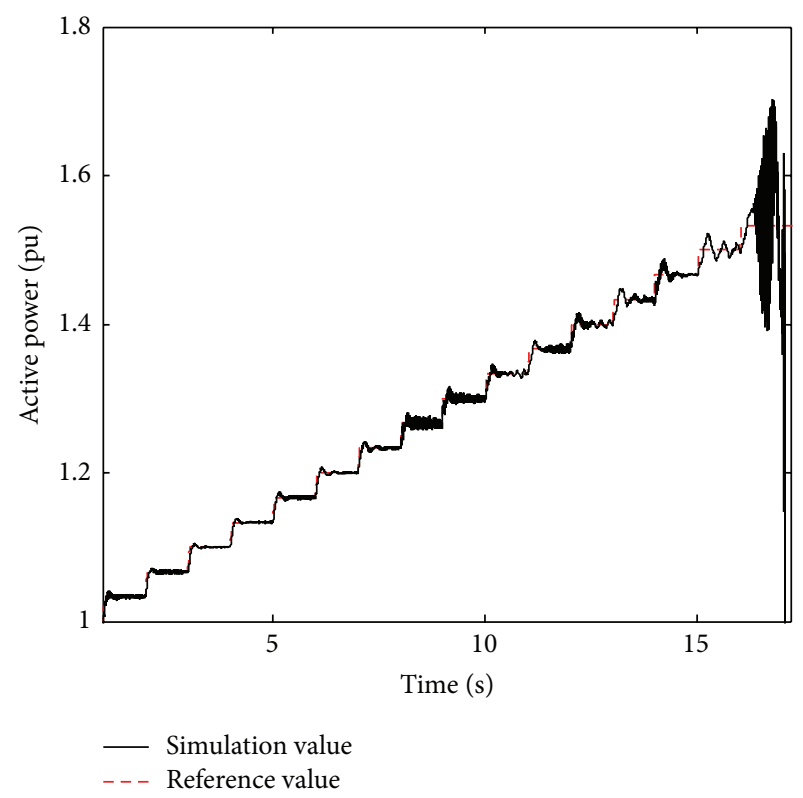

(a) Rectifying operation

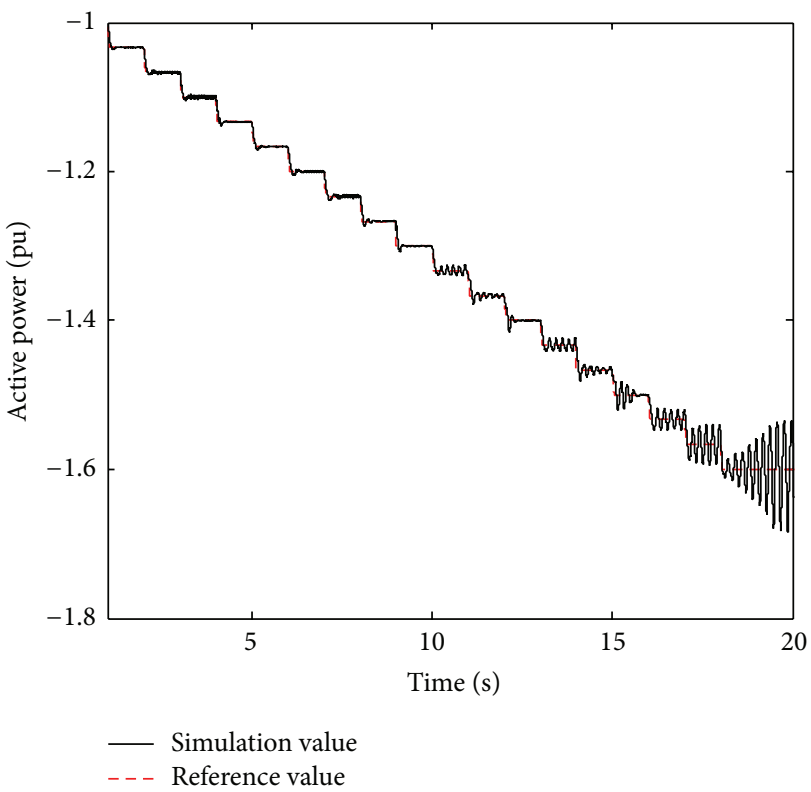

(b) Inverting operation

FIgURE 11: The simulation results of system with proposed PLL control.

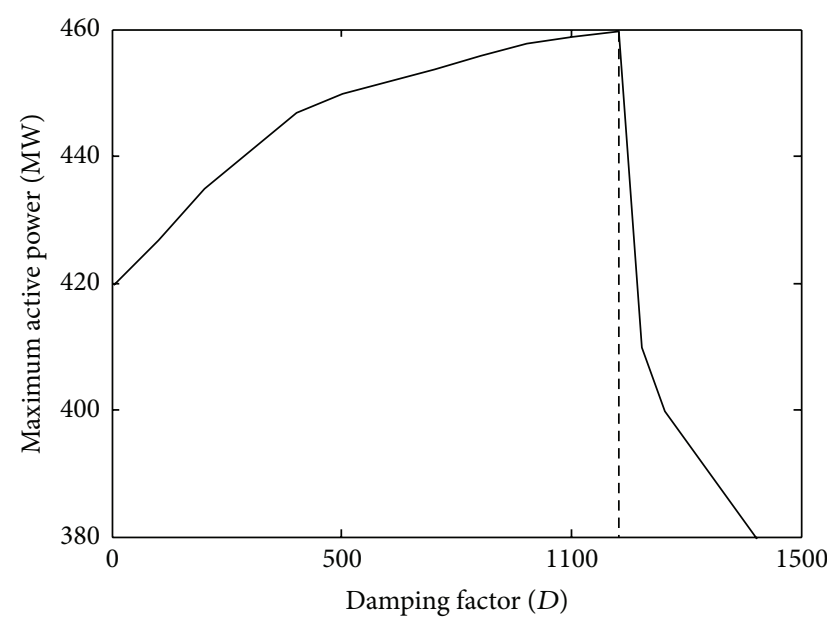

(a) Rectifying operation

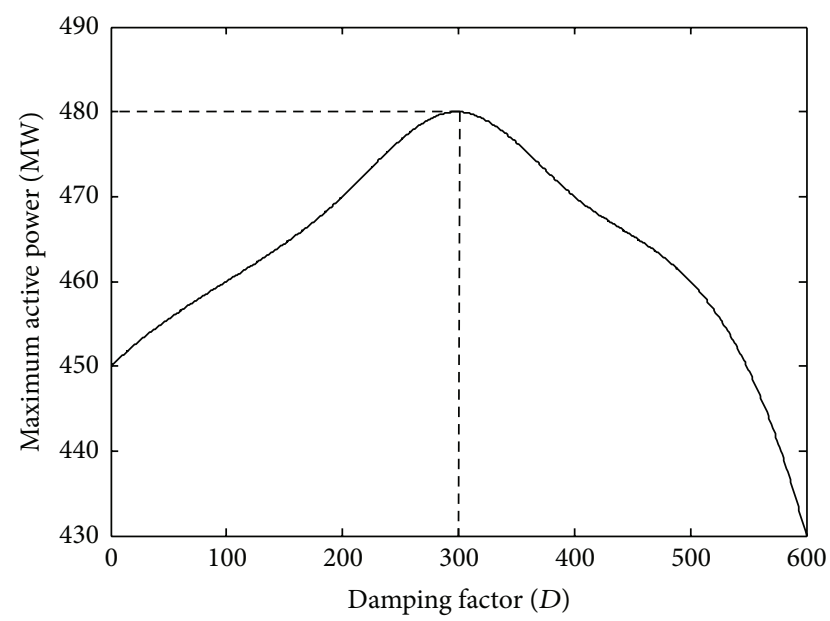

(b) Inverting operation

FIgURE 12: The relationship between $D$ and limits of power transmission.

The test model adopts $85^{\circ}$ as the AC system impedance angle. Compared with $420 \mathrm{MW}$, the maximum active power at rectifier is enhanced to $460 \mathrm{MW}$. Meanwhile, the limits of power transmission at inverter are enhanced from $450 \mathrm{MW}$ to $480 \mathrm{MW}$. The optimal value of damping factor $D$ calculated at rectifying operation is 1100 and is 300 at inverting operation. Figure 12 shows the relationship between VSC power transfer limitations and damping factors in the proposed PLL control.

It can be seen from Figure 12 that the optimal values of damping factors are approximately equal to the calculated results (1100 and 300, resp.). Figure 13 shows the simulation results of the relationship between system impedance angles and power transfer limitations with $D$ being equal to zero and the optimal values (i.e., 1100 and 300 , resp.).

Note that the power transfer limitation increments are shown in Figure 13 using arrows. The validity of the advanced PLL control strategy and the previous impedance angle analysis results are simultaneously validated in Figure 13.

\section{Conclusions}

In this paper, based on small-signal analysis and statespace matrix, the power transfer limitations of VSC linked with weak AC system are analyzed. Besides, the dynamic model with vector-current control is developed to evaluate 
TABLE 7: Limits of power transmission with different $\varphi$.

\begin{tabular}{|c|c|c|}
\hline$\varphi$ & $\begin{array}{c}\text { Max } P \\
\text { (rectifying operation) }\end{array}$ & $\begin{array}{c}\text { Max } P \\
\text { (inverting operation) }\end{array}$ \\
\hline $80^{\circ}$ & $385 \mathrm{MW}(1.283 \mathrm{pu})$ & $460 \mathrm{MW}(1.533 \mathrm{pu})$ \\
\hline $81^{\circ}$ & $390 \mathrm{MW}(1.300 \mathrm{pu})$ & $458 \mathrm{MW}(1.527 \mathrm{pu})$ \\
\hline $82^{\circ}$ & $397 \mathrm{MW}(1.323 \mathrm{pu})$ & $456 \mathrm{MW}(1.520 \mathrm{pu})$ \\
\hline $83^{\circ}$ & $408 \mathrm{MW}(1.360 \mathrm{pu})$ & $455 \mathrm{MW}(1.517 \mathrm{pu})$ \\
\hline $84^{\circ}$ & $415 \mathrm{MW}(1.383 \mathrm{pu})$ & $452 \mathrm{MW}(1.507 \mathrm{pu})$ \\
\hline $85^{\circ}$ & $420 \mathrm{MW}(1.400 \mathrm{pu})$ & $450 \mathrm{MW}(1.500 \mathrm{pu})$ \\
\hline
\end{tabular}

the improved PLL control. The following conclusions are drawn:

(i) With the rising of active power at PCC, the stability of VSC system is getting worse and even unstable. The stable margin of VSC for rectifying operation is narrower than inverting situation. With the analysis of participation factor, the most sensitive parts to the stability margin are outer-loop control and PLL control.

(ii) The impedance angle of AC system has a great impact on the stable margin of VSC. For rectifying operation, with high impedance angle, the stability of system

A

$$
=\left(\begin{array}{ccccc}
-\frac{R_{g}}{L_{g}} & \omega & 0 & 0 & -\frac{1}{L_{g}} \\
-\omega & -\frac{R_{g}}{L_{g}} & 0 & 0 & 0 \\
0 & 0 & \frac{k_{p 1}\left(-(3 / 2) k_{\mathrm{pp}} v_{d 0}-1\right)-R_{c}}{L_{c}} & 0 & \frac{-3 k_{p 1} k_{\mathrm{pp}} i_{2 d 0}}{2 L_{c}} \\
0 & 0 & 0 & \frac{-k_{p 2}-R_{c}}{L_{c}} & -\frac{3}{2} k_{p 2} k_{\mathrm{pv}} \frac{v_{d 0}}{V_{0} L_{c}} \\
\frac{1}{C_{f}} & 0 & -\frac{1}{C_{f}} & 0 & 0 \\
0 & \frac{1}{C_{f}} & 0 & -\frac{1}{C_{f}} & -\omega \\
0 & 0 & \frac{3}{2} v_{d 0} & 0 & \frac{3}{2} i_{2 d 0} \\
0 & 0 & 0 & 0 & 1 \\
0 & 0 & -\frac{3}{2} k_{\mathrm{pp}} v_{d 0}-1 & -\frac{3}{2} k_{\mathrm{pp}} i_{2 d 0} \\
0 & 0 & 0 & 0 & -\frac{3}{2} k_{\mathrm{pv}} \frac{v_{d 0}}{V_{0}} \\
0 & 0 & 0 & 0 & 0 \\
0 & 0 & 0 & 0
\end{array}\right.
$$

The mathematical step in the derivation of the statevariable equations is given in this section:

$$
\begin{aligned}
& P=\frac{3}{2}\left(v_{d} i_{2 d}+v_{d} i_{2 q}\right), \\
& V=\sqrt{\frac{3}{2}} \sqrt{v_{d}^{2}+v_{q}^{2}} .
\end{aligned}
$$

is enhanced; and this is not the case for inverting operation. The damping characteristic of AC system can change the stable margin of VSC as well.

(iii) The proposed PLL control appends the damping factor $D$ into the existing PLL diagram to change the damping characteristic of VSC system. With the calculated optimal damping factors, the stable margins for VSC working in either rectifier or inverter modes are significantly enhanced.

\section{Appendix}

$$
\left.\begin{array}{ccccccc}
0 & 0 & 0 & 0 & 0 & -\frac{E_{m} \sin \delta_{0}}{L_{g}} & 0 \\
\frac{-\frac{1}{L_{g}}}{-3 k_{p 1} k_{\mathrm{pp}} i_{2 q 0}} & 0 & 0 & 0 & 0 & -\frac{E_{m} \cos \delta_{0}}{L_{g}} & 0 \\
\hline L_{c} & \frac{-k_{\mathrm{ip}} k_{p 1}}{L_{c}} & 0 & \frac{k_{i 1}}{L_{c}} & 0 & 0 & 0 \\
0 & 0 & -\frac{3}{2} k_{p 2} k_{\mathrm{iv}} \frac{v_{d 0}}{V_{0} L_{c}} & 0 & \frac{k_{i 2}}{L_{c}} & 0 & 0 \\
\omega & 0 & 0 & 0 & 0 & 0 & 0 \\
0 & 0 & 0 & 0 & 0 & 0 & 0 \\
\frac{3}{2} i_{2 q 0} & 0 & 0 & 0 & 0 & 0 & 0 \\
0 & 0 & 0 & 0 & 0 & 0 & 0 \\
-\frac{3}{2} k_{\mathrm{pp}} i_{2 q 0} & -k_{\mathrm{ip}} & 0 & 0 & 0 & 0 & 0 \\
0 & 0 & -\frac{3}{2} k_{\mathrm{iv}} \frac{v_{d 0}}{V_{0}} & 0 & 0 & 0 & 0 \\
k_{\mathrm{pll}} & 0 & 0 & 0 & 0 & 0 & c k_{\mathrm{pll}} \\
1 & 0 & 0 & 0 & 0 & 0 & 0
\end{array}\right) .
$$

The small-signal model is shown in (A.3). In particular, the quadrature component of the PCC voltage at operating point is $0\left(v_{q 0}=0\right)$ :

$$
\begin{aligned}
& \Delta P=\frac{3}{2}\left(\Delta v_{d} i_{2 d 0}+v_{d 0} \Delta i_{2 d}+\Delta v_{q} i_{2 q 0}\right), \\
& \Delta V=\frac{3}{2} \frac{v_{d 0}}{V_{0}} \Delta v_{d} .
\end{aligned}
$$




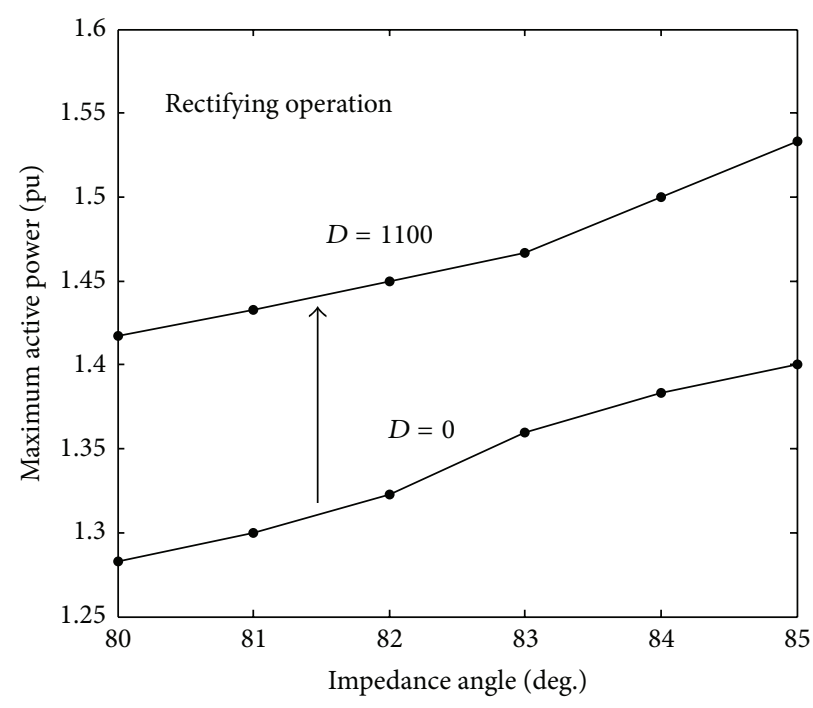

(a) Rectifying operation

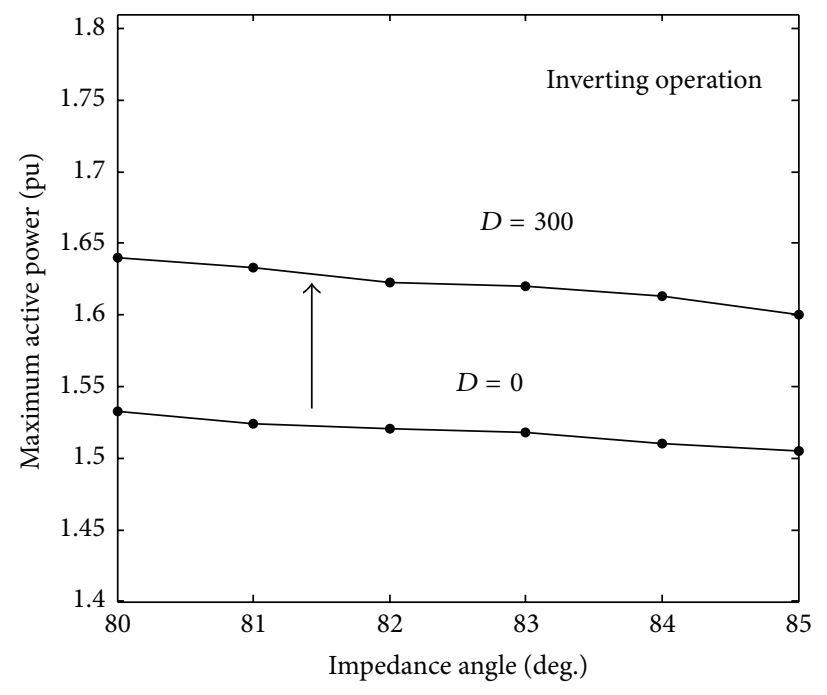

(b) Inverting operation

FIgURE 13: The power transfer limitations with the advanced PLL control.

The relationship between $e_{d}, e_{q}$, and $\theta$ is shown in (A.4), in which $\omega_{0} t+a_{0}$ is the real time angle of equivalent ac voltage source

$$
\begin{aligned}
& e_{d}=E_{m} \cos \left[\theta-\left(\omega_{0} t+\alpha_{0}\right)\right], \\
& e_{q}=-E_{m} \sin \left[\theta-\left(\omega_{0} t+\alpha_{0}\right)\right] .
\end{aligned}
$$

The small-signal model is shown in (A.5). $\delta$ is mentioned in nomenclature

$$
\begin{aligned}
& \Delta e_{d}=-E_{m} \sin \delta_{0} \Delta \theta, \\
& \Delta e_{q}=-E_{m} \cos \delta_{0} \Delta \theta .
\end{aligned}
$$

The small-signal model of (1) (4) is shown below

$$
\begin{aligned}
& {\left[\begin{array}{l}
-\left(E_{m} \sin \delta_{0}\right) \Delta \delta \\
-\left(E_{m} \cos \delta_{0}\right) \Delta \delta
\end{array}\right]-\left[\begin{array}{c}
\Delta v_{d} \\
\Delta v_{q}
\end{array}\right]} \\
& =R_{g}\left[\begin{array}{l}
\Delta i_{1 d} \\
\Delta i_{1 q}
\end{array}\right]+L_{g} \frac{d}{d t}\left[\begin{array}{c}
\Delta i_{1 d} \\
\Delta i_{1 q}
\end{array}\right]+\omega L_{g}\left[\begin{array}{c}
-\Delta i_{1 q} \\
\Delta i_{1 d}
\end{array}\right], \\
& {\left[\begin{array}{l}
\Delta v_{d} \\
\Delta v_{q}
\end{array}\right]-\left[\begin{array}{l}
\Delta v_{c d} \\
\Delta v_{c q}
\end{array}\right]} \\
& =R_{c}\left[\begin{array}{l}
\Delta i_{2 d} \\
\Delta i_{2 q}
\end{array}\right]+L_{c} \frac{d}{d t}\left[\begin{array}{l}
\Delta i_{2 d} \\
\Delta i_{2 q}
\end{array}\right]+\omega L_{c}\left[\begin{array}{c}
-\Delta i_{2 q} \\
\Delta i_{2 d}
\end{array}\right], \\
& {\left[\begin{array}{l}
\Delta i_{1 d} \\
\Delta i_{1 q}
\end{array}\right]-\left[\begin{array}{l}
\Delta i_{2 d} \\
\Delta i_{2 q}
\end{array}\right]=C_{f} \frac{d}{d t}\left[\begin{array}{l}
\Delta v_{d} \\
\Delta v_{q}
\end{array}\right]+\omega C_{f}\left[\begin{array}{c}
-\Delta v_{q} \\
\Delta v_{d}
\end{array}\right],} \\
& \left.-k_{\mathrm{pp}} \Delta P-k_{\mathrm{ip}}\right] \Delta P d t=\Delta i_{2 d \mathrm{ref},}
\end{aligned}
$$

$$
\begin{aligned}
& -k_{\mathrm{pv}} \Delta V-k_{\mathrm{iv}} \int \Delta V d t=\Delta i_{2 q \mathrm{ref}}, \\
& k_{p 1}\left(\Delta i_{2 d \mathrm{ref}}-\Delta i_{2 d}\right)+k_{i 1} \int\left(\Delta i_{2 d \mathrm{ref}}-\Delta i_{2 d}\right) d t \\
& =L_{c} \frac{d \Delta i_{2 d}}{d t}+R_{c} \Delta i_{2 d}, \\
& k_{p 2}\left(\Delta i_{2 q \mathrm{ref}}-\Delta i_{2 q}\right)+k_{i 2} \int\left(\Delta i_{2 q \mathrm{ref}}-\Delta i_{2 q}\right) d t \\
& =L_{c} \frac{d \Delta i_{2 q}}{d t}+R_{c} \Delta i_{2 q}, \\
& \Delta \omega=k_{\mathrm{pll}} \Delta v_{q}+c k_{\mathrm{pll}} \int \Delta v_{q} d t, \\
& \Delta \delta=\int \Delta \omega d t .
\end{aligned}
$$

The state-variables $\Delta x_{1}, \Delta x_{2}, \Delta x_{3}, \Delta x_{4}$, and $\Delta x_{5}$ are assumed below:

$$
\begin{aligned}
& \Delta x_{1}=\int \Delta P d t, \\
& \Delta x_{2}=\int \Delta v_{d} d t, \\
& \Delta x_{3}=\int\left(\Delta i_{2 d \text { ref }}-\Delta i_{2 d}\right) d t, \\
& \Delta x_{4}=\int\left(\Delta i_{2 q \text { ref }}-\Delta i_{2 q}\right) d t, \\
& \Delta x_{5}=\int \Delta v_{q} d t .
\end{aligned}
$$


With the improved PLL control, matrix $\mathbf{A}$ is changed. The modified elements are shown below. "+" is for rectifying operation and "-" is for inverting operation:

$$
\begin{aligned}
& \mathbf{A}_{11,3}= \pm D\left(\frac{3}{2} k_{\mathrm{pp}} v_{d 0}+1\right), \\
& \mathbf{A}_{11,5}= \pm \frac{3}{2} D k_{\mathrm{pp}} i_{2 d 0}, \\
& \mathbf{A}_{11,6}=\left( \pm \frac{3}{2} D k_{\mathrm{pp}} i_{2 q 0}+k_{\mathrm{pll}}\right), \\
& \mathbf{A}_{11,7}= \pm D k_{\mathrm{ip}} .
\end{aligned}
$$

The participation factor mentioned in Section 2 is defined as the relativity between the $k$ th state-variable and the eigenvalue $\lambda_{i}$. The calculation method is shown in

$$
p_{k i}=\left|\frac{v_{k i} u_{k i}}{\mathbf{v}_{i}^{T} \mathbf{u}_{i}}\right|,
$$

in which $\mathbf{u}$ and $\mathbf{v}$ are the left eigenvector and right eigenvector separately. $v_{k i}$ and $u_{k i}$ are the corresponding elements in eigenvectors.

\section{Nomenclature}

$e_{a b c}: \quad$ Thévenin equivalent voltage of AC system

$v_{a b c}: \quad$ PCC voltage

$v_{c a b c}: \quad$ Converter voltage

$i_{1 a b c}$ : Phase current at the system side

$i_{2 a b c}$ : Phase current at the converter side

$i_{c a b c}: \quad$ Phase current in shunt capacitor

$P, V: \quad$ PCC active power and voltage

$P_{\text {ref }}, V_{\text {ref }}$ : The reference value of PCC active power and voltage

$e_{d}, e_{q}: \quad d$ and $q$ components of AC source voltage

$v_{d}, v_{q}: \quad d$ and $q$ components of PCC voltage

$v_{c d}, v_{c q}: \quad d$ and $q$ components of converter voltage

$i_{1 d}, i_{1 q}: \quad d$ and $q$ components of system current

$i_{2 d}, i_{2 q}: \quad d$ and $q$ components of converter current

$i_{c d}, i_{c q}: \quad d$ and $q$ components of capacitor current

$R_{g}, L_{g}$ : Equivalent resistance and inductance of ac system

$R_{c}, L_{c}: \quad$ Resistance and inductance of converter

$C_{f}: \quad$ Shunt capacitance

$i_{2 d \text { ref }}$ : $d$ component of converter current reference

$i_{2 q r e f}: \quad q$ component of converter current reference

$\omega: \quad$ Frequency of PCC voltage

$\theta: \quad$ PLL output angle

$\delta: \quad$ The angle PCC voltage $\mathbf{V}$ leading equivalent source voltage $\mathbf{E}$

$\varphi: \quad$ Impedance angle of AC system

D: $\quad$ Damping factor in the improved PLL control

$U_{\mathrm{dc}}: \quad$ DC voltage $k_{\mathrm{pp}}, k_{\mathrm{ip}}$ : Power loop proportional and integrator gains

$k_{\mathrm{pv}}, k_{\mathrm{iv}}$ : Voltage loop proportional and integrator gains

$k_{p 1}, k_{i 1}$ : Inner-loop control ( $D$-axis current) proportional and integrator gains

$k_{p 2}, k_{i 2}$ : Inner-loop control (Q-axis current) proportional and integrator gains

$k_{\mathrm{pll}}, c k_{\mathrm{pll}}$ : Proportional and integrator gains of PLL

$p_{k i}: \quad$ Participation factor

$E_{m}: \quad$ Maximum instantaneous value of source voltage.

\section{Conflict of Interests}

The authors declare that there is no conflict of interests regarding the publication of this paper.

\section{Acknowledgments}

This work was supported in part by the National High Technology Research and Development Program of China (863 Program) (no. 2013AA050105), in part by the National Natural Science Foundation of China (no. 51177042), and in part by the Fundamental Research Funds for the Central Universities (no. 2015XS23 and no. 2015QN04).

\section{References}

[1] IEEE, "IEEE guide for planning dc links terminating at AC locations having low short-circuit capacities," IEEE Standard 1204-1997, 1997.

[2] A. Gole, V. K. Sood, and L. Mootoosamy, "Validation and analysis of a grid control system using D-Q-Z transformation for static compensator systems," in Proceedings of the Canadian Conference on Electrical and Computer Engineering, pp. 745758, Montreal, Canada, September 1989.

[3] K. Liao, Z.-Y. He, and B. Sun, "Small signal model for VSCHVDC connected DFIG-based offshore wind farms," Journal of Applied Mathematics, vol. 2014, Article ID 725209, 6 pages, 2014.

[4] M. Cespedes and J. Sun, "Adaptive control of grid-connected inverters based on online grid impedance measurements," IEEE Transactions on Sustainable Energy, vol. 5, no. 2, pp. 516-523, 2014.

[5] V. K. Sood, V. Khatri, and H. Jin, "Performance assessment using EMTP of two gate firing units for HVDC converters operating with weak AC systems," in Proceedings of the International Conference on Power Systems Transients (IPST '95), pp. 517-522, Lisbon, Portugal, September 1995.

[6] F. Wu, X.-P. Zhang, K. Godfrey, and P. Ju, "Small signal stability analysis and optimal control of a wind turbine with doubly fed induction generator," IET Generation, Transmission and Distribution, vol. 1, no. 5, pp. 751-760, 2007.

[7] K. M. Alawasa and Y. A.-R. I. Mohamed, "Impedance and damping characteristics of grid-connected VSCs with power synchronization control strategy," IEEE Transactions on Power Systems, vol. 30, no. 2, pp. 952-961, 2015.

[8] A. Egea-Alvarez, S. Fekriasl, F. Hassan, and O. Gomis-Bellmunt, "Advanced vector control for voltage source converters connected to weak ac grids," IEEE Transactions on Power Systems, vol. 30, no. 6, pp. 3072-3081, 2015. 
[9] L. Zhang, L. Harnefors, and H.-P. Nee, "Power-synchronization control of grid-connected voltage-source converters," IEEE Transactions on Power Systems, vol. 25, no. 2, pp. 809-820, 2010.

[10] J. Z. Zhou, H. Ding, S. Fan, Y. Zhang, and A. M. Gole, "Impact of short-circuit ratio and phase-locked-loop parameters on the small-signal behavior of a VSC-HVDC converter," IEEE Transactions on Power Delivery, vol. 29, no. 5, pp. 2287-2296, 2014.

[11] J. A. Suul, S. D’Arco, P. Rodriguez, and M. Molinas, "Extended stability range of weak grids with Voltage Source Converters through impedance-conditioned grid synchronization," in Proceedings of the 11th International Conference on $A C$ and $D C$ Power Transmission, pp. 1-10, Birmingham, UK, February 2015.

[12] S. V. Bozhko, R. V. Blasco-Giménez, R. Li, J. C. Clare, and G. M. Asher, "Control of offshore DFIG-based wind farm grid with line-commutated HVDC connection," IEEE Transactions on Energy Conversion, vol. 22, no. 1, pp. 71-78, 2007.

[13] T. Midtsund, J. A. Suul, and T. Undeland, "Evaluation of current controller performance and stability for voltage source converters connected to a weak grid," in Proceedings of the 2nd International Symposium on Power Electronics for Distributed Generation Systems, pp. 382-388, IEEE, Hefei, China, June 2010.

[14] Z. Miao, L. Fan, D. Osborn, and S. Yuvarajan, "Wind farms with HVdc delivery in inertial response and primary frequency control," IEEE Transactions on Energy Conversion, vol. 25, no. 4, pp. 1171-1178, 2010.

[15] J. Zhu, C. D. Booth, G. P. Adam, A. J. Roscoe, and C. G. Bright, "Inertia emulation control strategy for VSC-HVDC transmission systems," IEEE Transactions on Power Systems, vol. 28, no. 2, pp. 1277-1287, 2013.

[16] H. Ding, S. Fan, J. Z. Zhou, Y. Zhang, and A. M. Gole, "Parametric analysis of the stability of VSC-HVDC converters," in Proceedings of the 11th IET International Conference on AC and DC Power Transmission, pp. 1-6, IEEE, Birmingham, UK, February 2015.

[17] B. Wen, D. Boroyevich, R. Burgos, P. Mattavelli, and Z. Shen, "Analysis of D-Q small-signal impedance of grid-tied inverters," IEEE Transactions on Power Electronics, vol. 31, no. 1, pp. 675687, 2016.

[18] A. Yazdani and R. Iravani, Voltage-Sourced Converters in Power Systems, Wiley, Hoboken, NJ, USA, 2010.

[19] G.-C. Hsieh and J. C. Hung, "Phase-locked loop techniques-a survey," IEEE Transactions on Industrial Electronics, vol. 43, no. 6, pp. 609-615, 1996.

[20] G. F. Franklin, J. D. Powell, and A. Emami-Naeini, Feedback Control of Dynamic Systems, Prentice Hall, New York, NY, USA, 2005.

[21] P. Kundur, Power System Stability and Control, McGraw-Hill, New York, NY, USA, 1993.

[22] D. Dong, J. Li, D. Boroyevich, P. Mattavelli, I. Cvetkovic, and Y. Xue, "Frequency behavior and its stability of grid-interface converter in distributed generation systems," in Proceedings of the 27th IEEE Applied Power Electronics Conference and Exposition (APEC '12), pp. 1887-1893, IEEE, Orlando, Fla, USA, February 2012.

[23] J. Beerten, S. D’Arco, and J. A. Suul, "Identification and smallsignal analysis of interaction modes in VSC MTDC systems," IEEE Transactions on Power Delivery, 2015. 


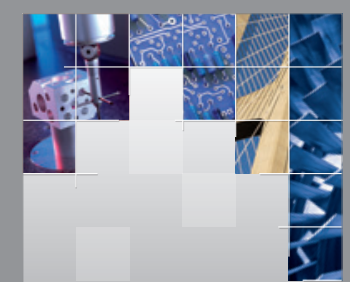

\section{Enfincering}
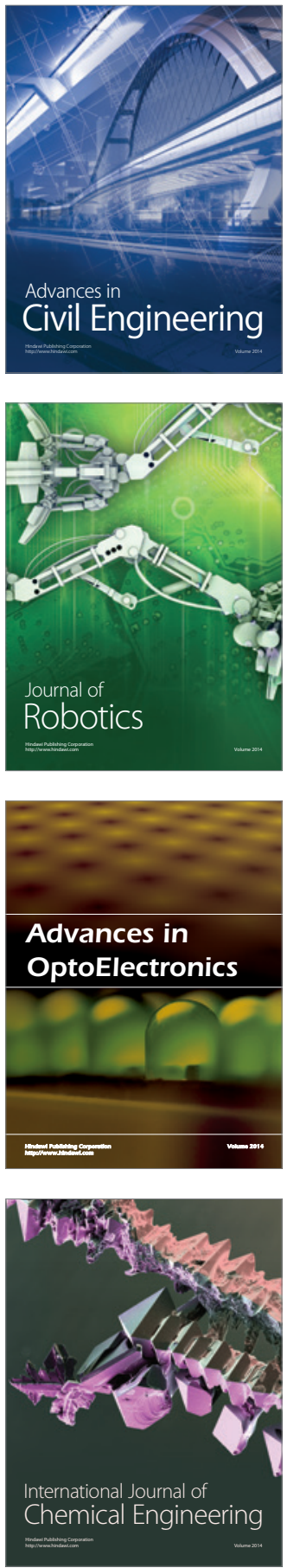

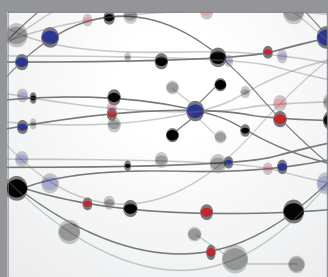

The Scientific World Journal

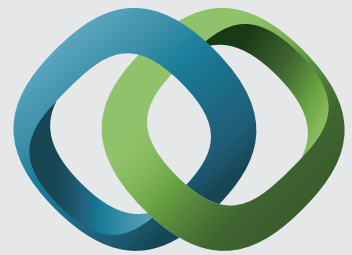

\section{Hindawi}

Submit your manuscripts at

http://www.hindawi.com
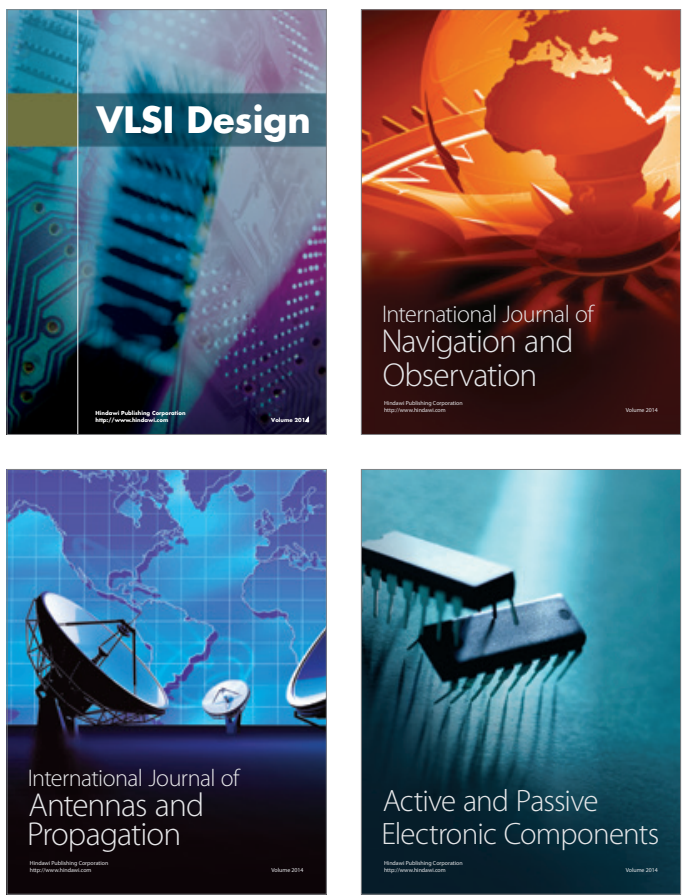
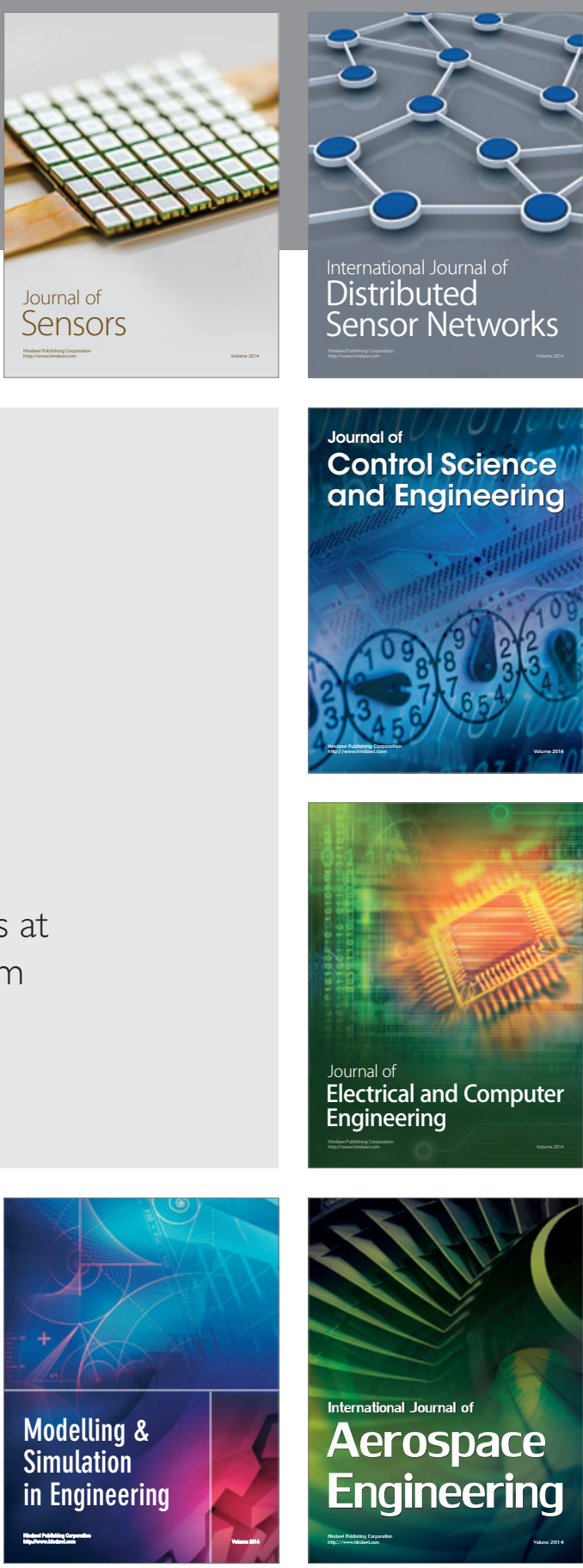

International Journal of

Distributed

Sensor Networks

Journal of

Control Science

and Engineering
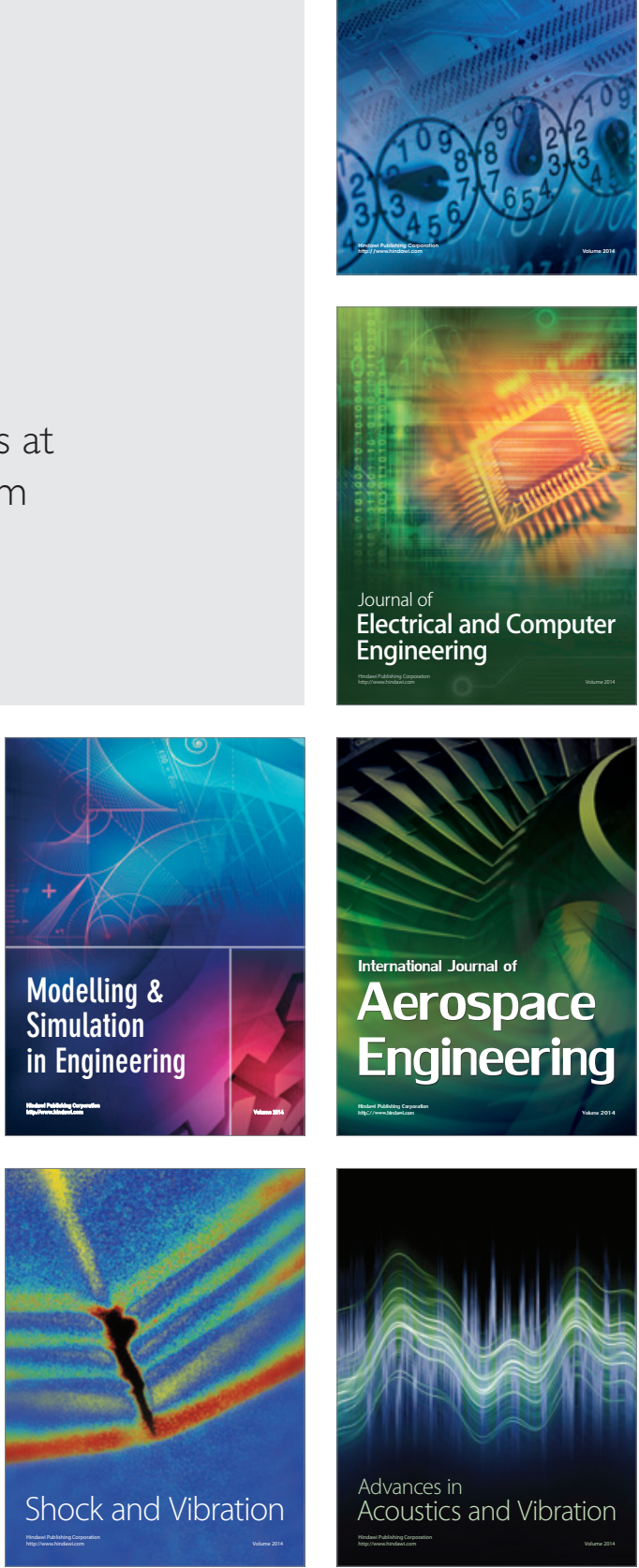